\title{
1. Wellbeing in politics and policy
}

\section{INTRODUCTION}

The past decade has seen a dramatic increase in governmental interest in the idea of wellbeing. ${ }^{1}$ At the international level, there are initiatives in place within the EU, OECD and UN, and at the national level within states as diverse and geographically spread as Australia, Bhutan, Ecuador, France and Morocco. In the UK, which has been prominent in developments, David Cameron has argued that 'Improving our society's sense of well-being is ... the central political challenge of our time' (Cameron 2006).

While in some respects this interest is new - marked by a proliferation of new measurement instruments, shifts in discourse and experimentation in policy - it has a long lineage. Debates on the 'good life' and how the state might contribute to this goal date back at least as far as the ancient Greeks. Similarly, attempts at measuring wellbeing 'can be traced back as far as one likes' (Allin and Hand 2014, 3). However, current interest is part of the second of two 'waves' of activity since the Second World War (Chapter 3), both of which have centred on a critique of gross domestic product (GDP) as the dominant indicator of societal progress.

The growth rate of GDP has become institutionalised as a beacon for politicians and a lodestar for policymakers. It emerged in the context of an economic crisis in the 1930s when the need to increase output was paramount. Its success in highlighting and helping to revive national economic fortunes meant that it was soon taken as a proxy for overall progress (Scrivens and Iasiello 2010, 18). Yet this is a role for which it was never intended. The person most closely associated with the development and institutionalisation of GDP, Simon Kuznets (1934) stated that 'The welfare of a nation can scarcely be inferred from a measurement of national income'. Yet, long after it served its immediate purpose, it has remained emblematic of a nation's welfare. This is the consequence of a 'cultural lag' (Layard 2005a, 60) in which 'market democracies, by the logic of their own success, continue to emphasize the themes that have brought them to their current position' (McKibben 2007, 43). 
As early as the 1960s, the limitations of GDP as a measure of progress were being highlighted by high-profile figures. In 1968, US presidential candidate Senator Robert Kennedy stated that gross national product $(\mathrm{GNP})^{2}$

counts air pollution and cigarette advertising, and ambulances to clear our highways of carnage. It counts special locks for our doors and the jails for the people who break them. It counts the destruction of the redwood and the loss of our natural wonder in chaotic sprawl. It counts napalm and counts nuclear warheads and armored cars for the police to fight the riots in our cities. It counts Whitman's rifle and Speck's knife, and the television programs which glorify violence in order to sell toys to our children ... it measures everything in short, except that which makes life worthwhile. And it can tell us everything about America except why we are proud that we are Americans.

This first wave critique of GDP led to the emergence of a social indicators movement and the development of new social surveys in a number of countries. But the impact of these developments on politics and policy was limited as the movement ran out of steam in the 1970s in the context of recession (Chapter 3). The second wave emerged in the 1990s in the context of environmental challenges, increased understanding of the drivers of wellbeing and growing acceptance of the value of measuring subjective wellbeing ${ }^{3}$ for public policy purposes. It is marked by the development of multi-dimensional frameworks for measuring progress that seek to challenge the GDP-dominated focus. This second wave has gone considerably further than the first in terms of both developing such frameworks and in persuading politicians and policymakers that they offer potential for use in policy (Chapter 3). Moreover, while the first wave challenge related primarily to advanced industrial nations, the second wave challenge reaches further, with significant momentum in, and relating to, developing countries (Boarini et al. 2014, 5).

The broader nature of the second wave is reflected in the development of new measurement frameworks both within international and supranational organisations ${ }^{4}$ (Chapter 3 ) as well as in a wide range of national contexts (Chapter 4). One estimate puts the number of new measurement initiatives at over 160 (Allin and Hand 2014, 258). At the international level, for example, the OECD Better Life Index is intended to "promote the measurement of well-being and embed the notion at the core of policy-making' (Boarini et al. 2014, 9). At the national level, the UK's Measuring National Well-being programme is, according to the Prime Minister, 'measuring our progress as a country, not just by how our economy is growing, but by how our lives are improving; not just by our standard of living, but by our quality of life' (Cameron 2010). 
If the rise of GDP helped elevate economics from the margins of politics and public policy to the 'ultimate authority' after the War (Cobb et al. 1995), these developments present a challenge for orthodox economics, which eschews subjective wellbeing indicators and instead focuses on 'utility' (pleasure or satisfaction) as measured through 'revealed preferences'. In this approach, 'an orthodox economist can tell what makes someone happy by what they do. If they buy a Ford Expedition, then ipso facto a Ford Expedition is what makes them happy' (McKibben 2007, 30). Its simplicity is central to its attractiveness: 'It reassures the politician that all his efforts to increase GNP are sensible and rational even when they may seem otherwise' and provides 'perhaps the central assumption of the world we live in: you can tell who I really am by how I spend' (McKibben 2007, 30).

Yet if the idea of wellbeing presents a challenge to economics, this is also a discipline that has in some quarters embraced this challenge. Indeed the work of the economist Richard Easterlin was a pivotal moment in research on the determinants of wellbeing. In 1974, Easterlin found that while higher incomes do correlate with higher levels of happiness, there are diminishing marginal returns to wellbeing from GDP and beyond a certain point of income happiness levels remain relatively flat. This finding became commonly known as the 'Easterlin Paradox'. While aspects of this paradox remain contested (see Graham et al. 2010), it challenged key assumptions in the field. Numerous economists have built on this work to play a central role in the current understanding of how wellbeing should be understood, measured and potentially used in public policy. ${ }^{5}$

While the idea of wellbeing presents a challenge to economics, the same is true for politics. Unlike economics, however, the politics discipline has been relatively silent on the issue. This may be understandable insofar as the issue has only recently begun to appear on government agendas. Yet its emergence is the outcome of a process that has been gestating for some time, and is one that has transformative potential in politics and policy. As Kroll $(2011,1)$ has argued:

The current debate on measuring progress and well-being is rapidly gaining importance throughout the world. Efforts to this end have the potential to bring about a real paradigm shift concerning what we as a society consider to be progress and how, as a consequence, we will shape how we live together.

Such developments demand the attention of political analysts. Moreover, it is politics and not economics that will ultimately determine the destiny of this agenda. 
It is for these reasons that this book provides the first theoretically and empirically informed analysis of the rise and significance of wellbeing in politics and policy. Specifically, we address two main questions:

1. How and why has the idea of wellbeing risen up the political agenda?

2. What are the policy implications of the rising political interest in the idea of wellbeing?

In addressing these questions we apply theories of the policy process, which we critique and seek to develop in light of the empirical material presented (Chapter 7).

As we elaborate in Chapter 2, the rise of wellbeing has to be understood in the context of multi-level governance, in which actors at different levels and from different sectors (public, private and voluntary) share and contest policy competences within territorially overarching policy networks (Hooghe and Marks 2001). Thus, our empirical focus begins with the rise of wellbeing at the international level before turning to a comparative analysis of developments in two political systems: the UK and the EU. Throughout the book we pay particular attention to the $\mathrm{UK}^{6}$ because of its prominence in the politics and policy of wellbeing.

While states other than the UK, such as Australia, Bhutan and France, can also claim to be at the forefront of wellbeing developments (Chapter 4), the UK case offers a distinctive combination of features that make it particularly worthy of close attention. First, it was an early mover in governmental attempts to measure subjective wellbeing through the introduction of sustainable indicators in the 1990s. These were to influence subsequent measurement initiatives at both national and international levels (Chapter 4). Second, the UK has remained closely connected to developments within international organisations, not least those in the EU, where it is formally connected to measurement processes as part of the European Statistical System (Chapter 4). These close connections provide insights into the two-way flow of ideas between national and international levels. Third, and perhaps most important for the second question of this book, wellbeing has been embraced at the highest political level in the UK with the explicit support of the Prime Minister. As a consequence, it is the country that has arguably gone furthest in seeking to bring wellbeing into policy (Chapter 5).

Our research draws on almost 100 semi-structured interviews with actors from a range of national and international organisations over a five-year period (2011-15). ${ }^{7}$ The interviews in $2011^{8}$ provided insights while crucial events were either fresh in the mind or still unfolding and 
were particularly important to understanding the rise of wellbeing. The later interviews were critical for understanding the emerging significance of the rise of wellbeing. In addition, we were able to draw on insights from The Politics of Wellbeing seminar series, ${ }^{9}$ which brought together over 100 academics, policymakers, think tank officials and others over six events between 2013 and 2015, and from engagement in the What Works Centre for Wellbeing, which began its work in June 2015. ${ }^{10}$

\section{THE IDEA OF WELLBEING}

As noted above, the idea of wellbeing can be traced back at least to the ancient Greeks. From these early debates, differences emerged on what constitutes a good life. Different conceptions of wellbeing frame the ways in which wellbeing can and should be pursued, either by the individual, by society, or by government. ${ }^{11}$ For example, Aristotle spoke of 'eudaimonia' or human flourishing as the highest purpose in life and one that was achievable through the continuous action and experience of living: 'doing' and 'being'. The Aristotelian tradition lives on in the contemporary work of Amartya Sen and Martha Nussbaum, among others, whose 'capabilities approach' has influenced development policy and its related measurement frameworks in particular (see Chapter 3). This approach suggests that the socio-political objective should be the provision of conditions that allow people to develop the 'capability sets' through which they can achieve their full potential and find purpose in life. These capabilities include the provision of human needs such as education and health and thus this approach identifies an explicit role for government.

By contrast, hedonistic accounts such as those associated with Utilitarianism (Bentham 1996 [1823]; Mill 2001 [1863]) identify happiness the experience of pleasure and the absence of pain - as the ultimate goal. Hedonistic accounts place the emphasis on personal feelings and experience, and in turn privilege the role of the individual in defining and attaining wellbeing. This preference for focusing on the individual is pervasive within neoclassical economics, in which it is assumed that the individual will purchase or behave rationally in the pursuit of their own 'utility' or wellbeing. The hedonic tradition is also prominent in current wellbeing debates, with influential scholars such as Layard (2005a, 147) suggesting that 'happiness should become the goal of policy'.

Thus, long-standing philosophical debates reverberate within contemporary wellbeing developments. Contestation over the definition, measurement and responsibility for wellbeing are a central feature of 
attempts to bring wellbeing into policy: it is a 'wicked problem' that combines complexity, uncertainty and divergence (Chapter 6). That there are no definitive answers to the policy challenge ensures that politics is at the heart of developments. So while there is increasing agreement that GDP growth is not fit for the purpose of measuring societal progress, different actors emphasise different themes in seeking to challenge its dominance: some are most concerned with promoting happiness or mental wellbeing (Layard 2005a), for others it is social issues (Wilkinson and Pickett 2009) and for others still it is to foreground concerns around environmental sustainability (Jackson 2011) and so on. There are similar frame conflicts relating to who should take responsibility for action to promote wellbeing - government, society or the individual. Such debates illustrate the wicked nature of the issue.

However, there is an important distinction to be made between the challenge of measuring wellbeing and that of bringing wellbeing into policy. On the former, there is growing consensus among governments and international organisations on how it should be measured (Chapter 3 ). And, while there are differences over how much weight should be given to the different 'drivers' (or 'domains') of wellbeing, this strand of the agenda has developed apace. More contested is the issue of using wellbeing as a guide for policy: there is growing support for this in principle but still considerable uncertainty around this in practice (Chapter 5).

While at various points we distinguish between initiatives to measure wellbeing on the one hand and policy aimed at promoting wellbeing on the other, in many respects they are two sides of the same coin: measurement indicators are central to framing policy debate. Thus, it is often said that we not only 'measure what we treasure' but also that we 'treasure what we measure': the decision by governments to give attention to indicators is generally followed by policy action. This point is well illustrated by the impact of GDP growth as an indicator, both in terms of shaping the overarching goals of government policy and in the related assumptions it brings to framing policymaking at other levels (Chapter 5). Statistical indicators are not neutral, either in the way they are constructed or in their effect, but are 'discursive elements' (OrtegaCerdà 2005). Moreover, in the second wave, statistical shortcomings are seen as a contributory factor to the economic crisis and thus improvements in key indicators are viewed as part of the solution. In 2009, President Sarkozy of France stated:

For years statistics have registered an increasingly strong economic growth as a victory over shortage until it emerged that this growth was destroying more 
than it was creating ... The crisis doesn't only make us free to imagine other models, another future, another world. It obliges us to do so. ${ }^{12}$

In a similar vein, Pier Carlo Padoan, Deputy Secretary-General and Chief Economist of the OECD suggested that

the crisis has not just highlighted areas where our statistical capacity remains deficient, but it has also undermined the confidence of people in markets, public policies, and official statistics. Restoring confidence requires providing evidence of what matters to people's everyday lives. ${ }^{13}$

The Commission established by Sarkozy on the Measurement of Economic Performance and Social Progress (CMEPSP) (2008-09) - which is variously referred to as the Sarkozy Commission, Stiglitz Commission, Stiglitz-Sen Commission or Stiglitz-Sen-Fitoussi Commission ${ }^{14}$ accelerated developments in a range of contexts (Chapters 3 and 4). Much of the debate that it generated focused on one of the key demands of the report: that subjective wellbeing indicators should be used alongside more objective indicators in measuring progress and guiding policy.

Subjective wellbeing has long been controversial and has traditionally been avoided by policymakers but interest in this area is a central feature of second wave developments (Chapter 3) and provides a novel twist to established ways of seeking to measure progress. Yet while subjective wellbeing is increasingly part of multi-dimensional wellbeing frameworks, it is still viewed with uncertainty in some contexts (Chapter 4). This is less so in the UK, where developments in terms of both measurement and other policy initiatives related to wellbeing are widely regarded as being among the most advanced (Kroll 2011, 5; ESRC 2014, 3; APPGWE 2014, 3).

\section{THE UK}

A pivotal moment in UK developments came in 2010 when the Prime Minister publicly endorsed the Office for National Statistics (ONS) Measuring National Well-being programme, which aims to 'develop and publish an accepted and trusted set of National Statistics which help people understand and monitor well-being' (Self et al. 2012, 8). In launching the programme, Cameron (2010) argued that it would

open up a national debate about what really matters, not just in government but amongst people who influence our lives: in the media; in business; the people who develop the products we use, who build the towns we live in, who 
shape the culture we enjoy. And second, this information will help government work out, with evidence, the best ways of trying to help to improve people's wellbeing.

The ONS subsequently conducted a series of public consultations on 'what matters' for wellbeing, which led to the Measuring National Well-being programme. A key part of this programme was the addition of four 'experimental' subjective wellbeing questions to the Annual Population Survey from April 2011 (Chapter 4).

Since the launch of the ONS programme there have been a number of related policy developments across UK government, which we discuss in Chapter 5. To date these generally amount to small-scale changes. However, this is generally viewed as a long-term process of change that is potentially transformative and could (and for some should) lead to a refocusing of government policy. In addition to Cameron's support for the agenda, in 2011 the Liberal Democrats (then in government) agreed a policy document that sought to put wellbeing at the 'heart of government policy' (Chapter 4). In 2014 the All Party Parliamentary Group on Wellbeing Economics spoke of 'setting government policy in the context of the overarching aim of promoting Wellbeing' (see Chapter 5). It is in this context that we consider the transformative potential of this agenda and specifically, following Kroll (2011), the prospects for a paradigm change resulting from this process (Chapter 5).

\section{THEORISING AGENDA-SETTING AND POLICY CHANGE}

In relation to the first question of the book, How and why has wellbeing risen up the political agenda?, we draw primarily on Kingdon's (2011) multiple streams approach to agenda-setting - a remarkably influential and resilient approach that was first published in 1984. ${ }^{15}$ Kingdon's central purpose is to try to explain why some ideas capture the imagination of politicians and policymakers at some moments, while others do not. He suggested that the phrase 'an idea whose time has come' captures 'a fundamental reality about an irresistible movement that sweeps over our politics and our society, pushing everything that might stand in its path' (Kingdon 2011, 1). Evidence that an idea's time has come is found in changes like marked shifts in public opinion and bandwagons onto which politicians of different persuasions climb (Kingdon 2011, 1). The notion of an idea 'sweeping' over politics resonates with the rise of wellbeing across national and international arenas. 
The multiple streams approach is particularly relevant to conditions of ambiguity, 'a state of having many ways of thinking about the same circumstances or phenomena' (Feldman 1989, 5): a key characteristic of wellbeing. The approach demands a focus on developments over a long period in order to understand the rise and fall of issues on agendas and the nature of change. Thus, while there has been a long-standing interest in the idea of wellbeing as a possible goal for government action, Kingdon's framework helps us to address the question of why now? in relation to its recent emergence on political agendas.

However, the case of wellbeing also provides an opportunity to test and develop Kingdon's approach. While the framework has proved relatively robust, there have also been recent calls for the approach to be applied in new arenas and in new ways (Zahariadis 2014). While the literature on agenda-setting has expanded beyond its US roots to studies of a wide range of other political systems (e.g., Uger and Yankaya 2008, Vliegenthart et al. 2011), studies of the UK remain relatively rare (Jennings et al. 2011, Zahariadis 2014) and so, until recently, have comparative studies of agenda-setting (Baumgartner et al. 2006, 959). Our detailed examination of the UK and the explicit comparative study of agenda-setting in the UK and EU systems thus both contribute to addressing these lacunae. Moreover, our consideration of international processes of policy diffusion alongside domestic analyses of agendasetting provide a novel conceptual framework for analysing externalinternal dynamics, which is crucial to understanding the rise of wellbeing.

In addressing the second question, What are the policy implications of the rising political interest in the idea of wellbeing?, we move beyond agenda-setting theory into theories of policy change. Our principal theoretical framework for addressing this question is Hall's (1993) influential conception of social learning (Chapter 2). ${ }^{16}$ Hall $(1993,278)$ identified policymaking as a process usually involving three variables: overarching policy goals that guide policy, the instruments or techniques used in seeking to attain these goals and the precise setting of the instruments. The central purpose of disaggregating policy in this way is to demonstrate that the dynamics at play are likely to vary according to these different variables. The relevance to wellbeing of disaggregating different aspects of policy is clear in even the basic distinction between measuring wellbeing and using wellbeing as a guide to policy. Beyond this broad differentiation are finer-grained distinctions for the types of policies that might emerge from the idea of wellbeing (Chapter 5). More specifically, Hall theorises the route to paradigm change in policy, which is identified as a possibility through wellbeing. Here we understand a 
policy paradigm to refer to widely shared ideas within the policy community (Baumgartner 2013, 251) and for paradigm change to imply 'fundamental realignment in most aspects of policy development' (Howlett and Cashore 2009, 36). More generally, Hall's social learning theory places a focus on ideas in policy change that provides a suitable complement to Kingdon's analysis of agenda-setting, which speaks directly to wellbeing as an 'idea' that has captured the attention of policymakers.

\section{THE STRUCTURE OF THE BOOK}

Chapter 2 sets out the theoretical framework for the book. In relation to our first question it outlines concepts that relate to the diffusion of ideas across boundaries before turning to Kingdon's multiple streams approach to understanding agenda-setting. This latter approach identifies three separate processes or 'streams' of problems, policies and politics that develop largely in isolation from each other but present the greatest opportunity for policy change when they are brought together. We then move on to outline the analytical framework for addressing our second question, which includes Hall's conception of social learning and contributions that subsequently developed this approach.

In Chapter 3 we outline our arguments concerning the two waves of wellbeing. We explain the rise and fall of the social indicators movement in the first wave and the distinctive features of the second wave. In this chapter we limit our discussion of the second wave to developments that have placed the issue on the agenda of major international organisations. These international developments further distinguish the second wave from the first wave and are important to developments in the specific political systems that we analyse in Chapter 4.

In Chapter 4 we consider how and why wellbeing has risen up the agenda in the UK, comparing developments with those in the EU. Comparison allows not only for a more systematic exploration of the key variables in policymaking in different contexts (e.g., the institutional structures, decision-making processes and the role of interest groups) but also the potential for understanding the exclusion of ideas from the agenda or 'non-decisions' (Bachrach and Baratz 1963). In each case, we structure the discussion through the multiple streams approach, considering in turn policy, politics and problem streams. The comparative analysis reveals both institutional and ideational biases that shape both the agenda-setting dynamics of the wellbeing issue in different contexts and that produce different emphases in approaches to measurement. 
In Chapter 5 we turn to the second main question of the book: what are the policy implications of the rising political interest in the idea of wellbeing? In addressing this question we focus on developments at the UK level, where there is high-level political commitment to using wellbeing in policy and where policy developments are seen as among the most advanced in the world. We employ Hall's framework of social learning to analyse UK policy developments, highlighting different policy variables and the prospect for different orders of change; specifically reflecting on the potential for fundamental realignment of most aspects of policy development or 'paradigm change'.

In Chapter 6 we reflect on controversies that are central to the prospects for wellbeing in policy. We focus on four issues in particular: reliability and validity (of data), responsibility (for action), distrust (of politicians) and distraction (from other concerns). We suggest that it is difficult to adjudicate between the various arguments as they often take very different starting points, either metatheoretical or disciplinary. So, in seeking to steer a course through these arguments we take the distinction between 'wicked' and 'tame' problems as a reference point, arguing that the challenge of bringing wellbeing into policy should be categorised as the former. In developing our arguments we ground them in relation to our empirical research on the UK, although a number of our arguments apply more generally.

In Chapter 7 we draw together the threads of the previous six chapters and reflect on the value of our theoretical frameworks in light of our findings. In doing so we suggest a synthesis of approaches that might be used in future research seeking to analyse the relationship between agenda-setting and paradigm change. We also discuss further the prospects for wellbeing in public policy and, specifically, the possibility of a 'third wave' of interest in which wellbeing is recognised as an important benchmark of progress, is internalised by key actors, is institutionalised in policy practices, and leads to policy changes that have a significant effect on the lives of citizens. ${ }^{17}$

\section{NOTES}

1. We use the terms 'wellbeing', 'quality of life' and 'happiness' where they have specific connotations but as a general term we adopt 'wellbeing' because it is the most commonplace of the three terms in policy debates. Moreover, while 'happiness' is generally seen as having the most specific meaning of these three terms, 'quality of life' and 'wellbeing' are broader concepts that are often used interchangeably by policymakers.

2. GNP refers to the total market value of goods and services produced by the residents of a country, even if they are living abroad. GDP refers to the market value of goods produced within a country's borders, and is now generally used as the benchmark for economic 
growth. So while Kennedy referred to GNP, GDP is now more commonly referred to by politicians and others.

3. Subjective wellbeing refers to people's own assessment of their lives. As Phillips (2006, 18) notes, subjective wellbeing is 'rather more complex than happiness'. It has been identified as having three components that can be treated as separate items: pleasant affect, unpleasant affect, and satisfaction (Diener and Lucas 1999; see also Chapter 3).

4. We make this distinction here to clarify the status of the EU as a supranational organisation, indicating that its power goes beyond that permitted to it by its national governments, whereas international organisations have no such power (Bache et al. 2015a, 565). However, for the sake of simplicity we use the term international organisation throughout the book to include the EU unless we are making points that relate specifically to the supranational status of the EU.

5. The membership of the Commission on the Measurement of Economic Performance and Social Progress (CMEPSP 2009) provides a starting point for identifying those who have contributed to this endeavour (see also Chapter 3 ).

6. In focusing closely on the UK we acknowledge that our approach is somewhat Anglocentric and a different account of developments may well emerge in different national contexts. While there are significant developments related to wellbeing within the devolved territories of Scotland, Wales and Northern Ireland (see Chapter 5, note 1) for the sake of consistency we focus on politics and policy at the UK level.

7. This includes politicians, civil servants, academics and officials from think tanks, non-governmental organisations, charities and interest groups.

8. These were part of a knowledge transfer project on The Politics and Policy of Wellbeing (2011). funded by the Higher Education Innovation Fund (HEIF) of the Higher Education Funding Council of England (HEFCE) for which Bache was Principal Investigator (PI).

9. Bache was PI for the seminar series on The Politics of Wellbeing which was funded by the UK Economic and Social Research Council (grant reference ES/L001357/1) (see: http:// politicsofwellbeing.group.shef.ac.uk/, accessed 7 September 2015).

10. Bache was a Co-Investigator of the ESRC project on Community Wellbeing, which was one of three initial projects funded at the launch of the What Works Centre for Wellbeing in June 2015 (grant reference ES/N003756/1). This research also draws on insights from interviews conducted by Reardon as part of her $\mathrm{PhD}$ on Quality of Life and Transport Policy (2011-14), which was also funded by the ESRC (grant reference ES/I023615/1).

11. Mulgan $(2014,283)$ notes that 'the overt aspiration for governments to increase happiness can be found in the Western, Islamic, Hindu, Chinese and Buddhist traditions'.

12. Sarkozy (2009a) quoted in Davies, L. (2009) 'Sarkozy attacks focus on economic growth', Guardian.co.uk, 14 September, accessed 7 September 2015 at http://www.theguardian.com/ business/2009/sep/14/sarkozy-attacks-gdp-focus.

13. Statistics for Policymaking: Europe 2020, Conference, Brussels, 10-11 March 2001.

14. The Commission was led by Nobel Prize winning economists Professor Joseph Stiglitz and Professor Amartya Sen as Chair and Chair Adviser respectively, and Professor Jean-Paul Fitoussi as the Commission's co-ordinator.

15. A total of 14,086 Google Scholar citations (7 December 2015).

16. A total of 4,850 Google Scholar citations (7 December 2015).

17. This book draws on material from a number of our existing publications, which we acknowledge here: Bache (2013), Bache and Reardon (2013), Bache (2015) and Bache, Reardon and Anand (2015). 